\title{
Introduction to the minimal access colorectal surgery supplement of Techniques in Coloproctology
}

\author{
S. D. Wexner
}

(C) Springer-Verlag Italia 2012

I am delighted to introduce our readers to this special supplemental issue of Techniques in Coloproctology. This issue is comprised of contributions from some of the world's most respected leading luminaries in minimally invasive surgery. It opens with a beautiful description of laparoscopic right hemicolectomy by Dr. Jason Wong and Dr. Maher Abbas. The step-by-step description is accompanied by a cogent explanation of why and how the authors perform these procedures. In a similar manner, Dr. Amit Khanna discusses laparoscopic total mesorectal excision. Dr. John Migaly and coauthors detail the history and current status of minimally invasive surgery for diverticulitis, and Dr. Meagan Costedio and Dr. Feza Remzi very deftly elucidate the current status of laparoscopic single-port colectomy. Dr. Mario Morino and coauthors provide an elegant overview of the development and resurgence of interest in transanal endoscopic microsurgery. Dr. Morris Franklin and coauthors detail not only the development and rationale behind natural orifice surgery, but also describe their own large personal series of natural orifice specimen extraction procedures. Along with his coauthors, Dr. Peter Marcello discusses his widely acclaimed technique of hand-assisted laparoscopic colorectal surgery and argues very compellingly for its adoption. Dr. Seth Stein and Dr. Roberto Bergamaschi offer us a comprehensive description of both intracorporeal and extracorporeal anastomosis and explain their own personal preferences. Dr. Seon Hahn Kim and Dr. Jung Myun Kwak expertly describe robotic total mesorectal excision. I would like to extend an extra note of appreciation to Drs. Khanna, Morino, Marcet, and Remzi, all of whom provided highquality videos which further enhance the educational value of this volume.

I wish to thank each and every author for their energy, efforts, time, and devotion to their respective subject matter. Together, they have elegantly created this issue which offers just the right amount of overlap to ensure complete comprehension while minimizing unnecessary redundancy. I am quite confident that every surgeon will enjoy reading this issue as much as I have enjoyed editing it. I wish to also thank my editor-in-chief, Dr. Mario Pescatori, and his co-editors Drs. Alberto Arezzo and Giuseppe Gagliardi for entrusting me with this important task. Lastly, I express my appreciation to my good friend, alumnus, and colleague Dr. Fabio M. Potenti for his invaluable assistance and expertise.

Conflict of interest There are no relevant financial disclosures to this introduction.

This issue is dedicated with much gratitude to my loyal trusted friends around the world who have supported my research and education mission throughout my career.

S. D. Wexner $(\square)$

Cleveland Clinic Florida, 2950 Cleveland Clinic Boulevard,

Weston, FL 33331, USA

e-mail: wexners@ccf.org 